\title{
An Analytical Study of DNA Sequence
}

\section{Basil Y. Thanoon}

basyttb@yahoo.com

College of Computer Sciences and

Mathematics

University of Mosul

Received on : 4/10/2010

\section{Fatima M Hasan}

Fatima.Zamzwm@yahoo.com

College of Computer Sciences and

Mathematics

University of Mosul

Accepted on : 10/11/2010

\section{ABSTRACT}

This paper contains a general introduction to Bioinformatics, theirs goals, objectives and their applied fields. Is then shed light on the real views of DNA of humans, some processors use mathematical and statistical analysis of the traditional purpose of these observations and to identify some features and characteristics. Graphical analysis of DNA is carried out in two and three dimensions. The interconnectedness among the sites of DNA is also analyzed as well as a spectral analysis. The attempt is also made to identify the order of such observations. Through this analytical study it is shown that DNA has a complex structure with interdependent with each other for long-term.

Keywords: Bioinformatics, spectral analysis , DNA

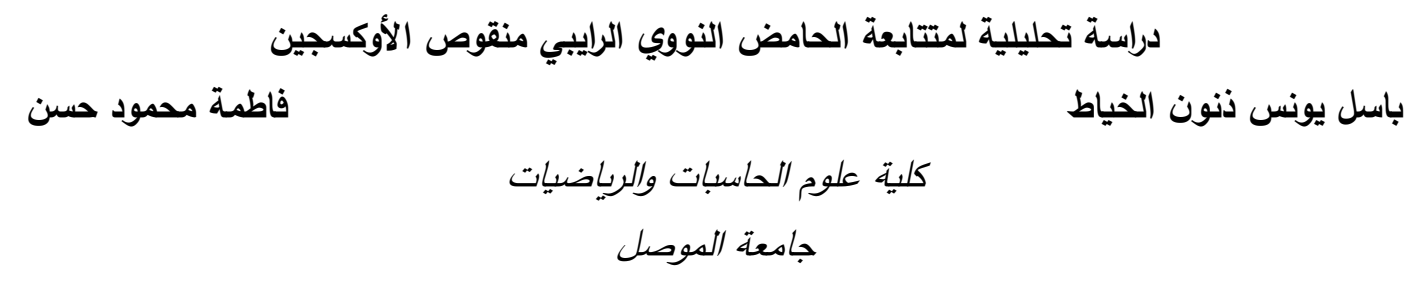

تاريخ قبول البحث:2010/11/10

تاريخ استلام البحث: 2010/10/4

\section{الملخص}

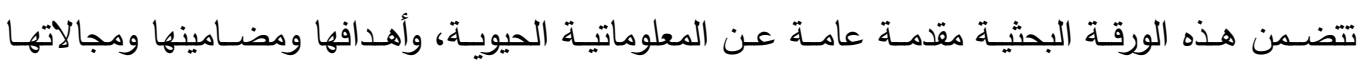

التطبيقية. كذلك يتم تسليط الأضواء على مشاهدات حقيقية للحامض النووي الرايبي منقوص الأوكسجين DNA

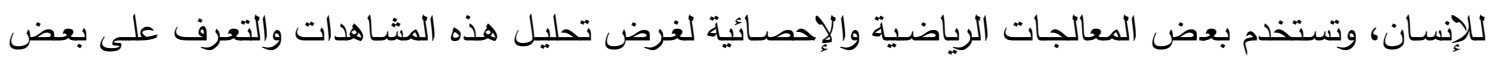

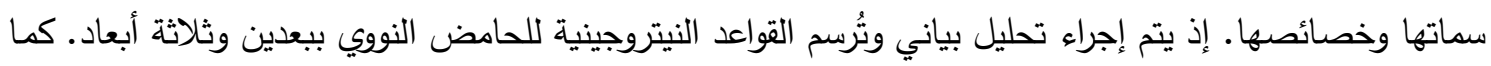
يُّرس الترابط الداخلي بين مواقع الحامض النووي ويجرى تحليلا طيفيا لمشاهدات الحامض النووي ـ وتُجرى أيضا

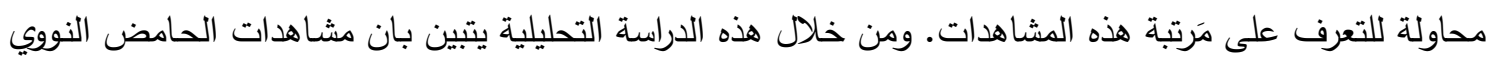
الرايبي منقوص الأوكسجين DNA للإنسان معقدة البنية التركيبية، ومترابطة مع بعضها البعض وعلى فتردة فلترات طويلة الأمد.

الكلمات المفتاحية: المعلوماتيه الحيويه , الحامض النووي الرايبي منقوص الأوكسجين DNA, الطيفي 
تُعرّف المعلوماتيـة الحيويـة على أنها استخدام الحاسوب لمعالجـة المعلومـات الحيويـة. وهو علم ركيزته

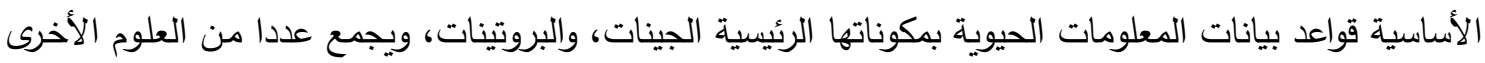

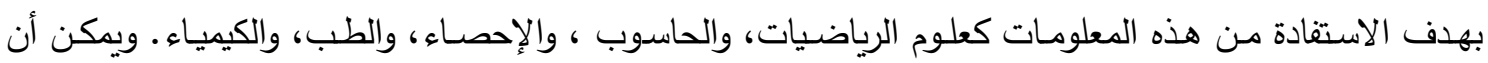
نلخص تعريف المعلوماتية الحيويـة على أنها تطبيق التقانة الحاسوبية والمعلوماتية في إدارة المعلومـات الحيويـة. ومثال ذلك تحليـل المعلومـات الحيويـة (الجينـات والبروتينـات) باستخدام الحاسـوب والتقنيـات الحاسوبية الحديثـة

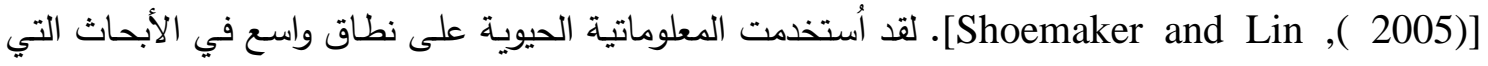
تخص مشروع الجينوم البشري والذي حدّد السلسلة الجينيّة الكاملة للإنسان، و هو الثورة الجديدة التي تعد تغيير وجه الطب الذي نعرفه اليوم وعلاج أمراض لم يكن لها علاج من قبل. كما أن للمعلوماتيـة الحيويـة دوراً كبيراً وفاعلا في اكتثـاف عقاقير جديدة وفعّالة، حيث ساهمت بشكل كبير في إيجاد حلول لتحليل النتائج المختبريـة المعقدة وكذلك استخدام الحاسوب لحفظ المعلومات واسترجاعها. كما أن البحث في المادة الوراثية للكائنات الحية يدخل ضمن نطاق المعلوماتية الحيوية، ويخدم هذا الفرع من العلم جميع العاملين في مجال الأبحاث العلمية الطبية

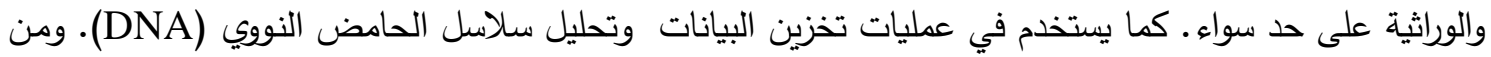
خلال المعلوماتية الحيوية يمكن أن نفهم بثكل أفضل الكيفية التي تتظم فيها الجينات في سلسلة الحامض النياه النووي (DNA)

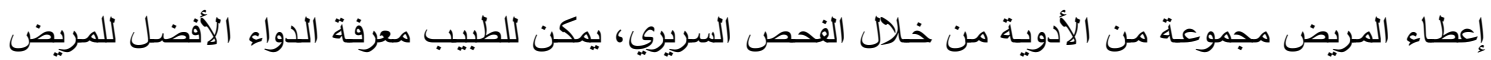
وتحديد حدة الاستجابة للدواء من خلال فحص المادة الوراثية للثخص ومقارنتها بالموجود في قواعد البيانات الجينية للأمراض ومن ثم التأكد إلى أي فئة ينتمي هذا المريض. وفي حأهي حالة الخطر يمكن تغيير الجرعة بدقة أو توجيه المريض لاستخدام دواء آخر وتغيير خطة العلاج بأكملها مما يجنب المريض مخاطر الأدوية قبل استخدامها (قاسم

تهدف المعلوماتية الحيوية إلى ثلاثة أهداف رئيسيّة وهي ( (Shoemaker and Lin): 1-تطوير تقنيات وبناء خوارزميات تساعد في تحصيل المعلومات من مجموعة ضخمة من البيانات. 2-تحليل وتفسير الأنماط المختلفة من البيانات التي تتضمن سلاسل الأحماض الأمينية والقطع والبنى البروتينيّة 3-تطوير وتتفيذ أدوات تساعد على إدارة فعَالة للأنماط المختلفة من المعلومات.

Data Mining تتضـمّن المعلوماتيـة الحيويـة المعالجـة البارعـة ، والتقصسي ، والتتقيب عن بيانـات

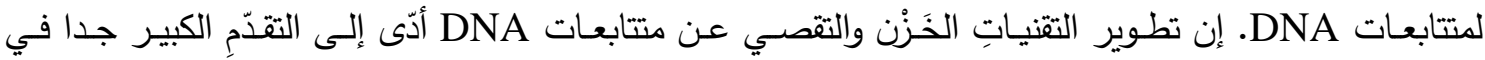

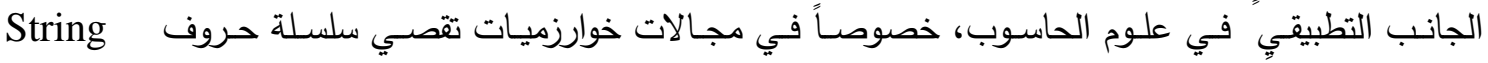
Database Theory ونظرية قاعدة البيانات الماكنة Machine Learning ونتِ Searching Algorithms إن التقصي عن متتابعات DNA يهتم بدراسة حدوثَ سلسلة حروف داخل سلسلة أكبر مِنْ الحروف، للتقصي عن متتابعـات معيّنة مِن النكليوتيدات Nucleotides. وتستعمل سلاسـل مـاركوف لتشـيص الأشـياء الثـاذّة 
Anomalies، وتصليح البيانات Repair Data، وتقييم سلامةَ البيانات Assess Data Integrity (الخياط

من المجالات التطبيقية للمعلوماتية الحيوية ما يأتي (Shoemaker and Lin (2005):

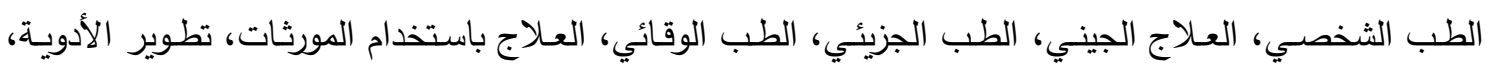

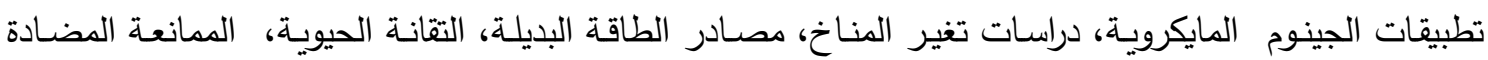

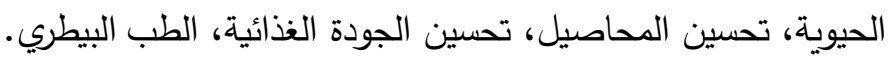

2. - الحامض النووي الرايبي منقوص الأوكسجين:

هو مختصر DNA بعضهما باتجاه عقارب السـاعة، حول محور واحد، أحدهما يتجها إلى أعلى والآخر إلى أسفل، على هيئة سلم

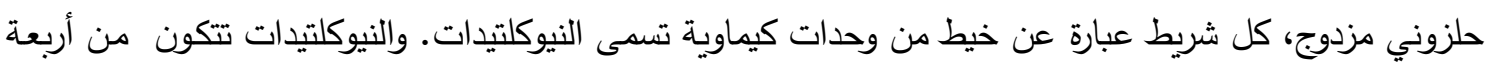
أصناف لا تختلف إلا في نوع القاعدة النيتروجينية، وهذه القواعد النيتروجينية هي:

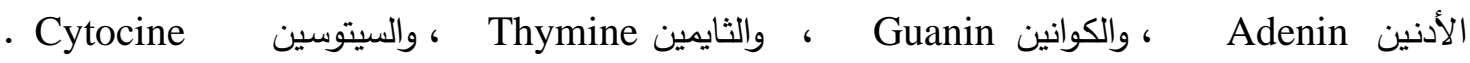
وتثكل هذه القواعد أزواجـا ، فقاعدة "الأدنين" ترتبط دائمـا بـ "الثايمين"، بينمـا ترتبط "الكوانين" بـ "السيتوسين". وتتوزع القواعد بالترتيب على اللولب المزدوج، وتثكل القواعد كلمات وجملا وراثية تحفظ المعلومات الوراثية للكائن

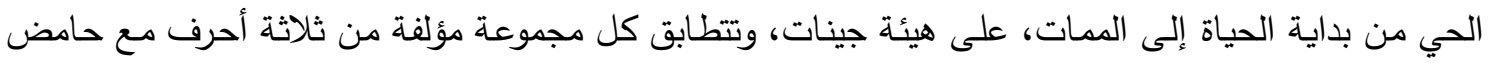
أميني واحد ، انظر الثكل (1) بانه

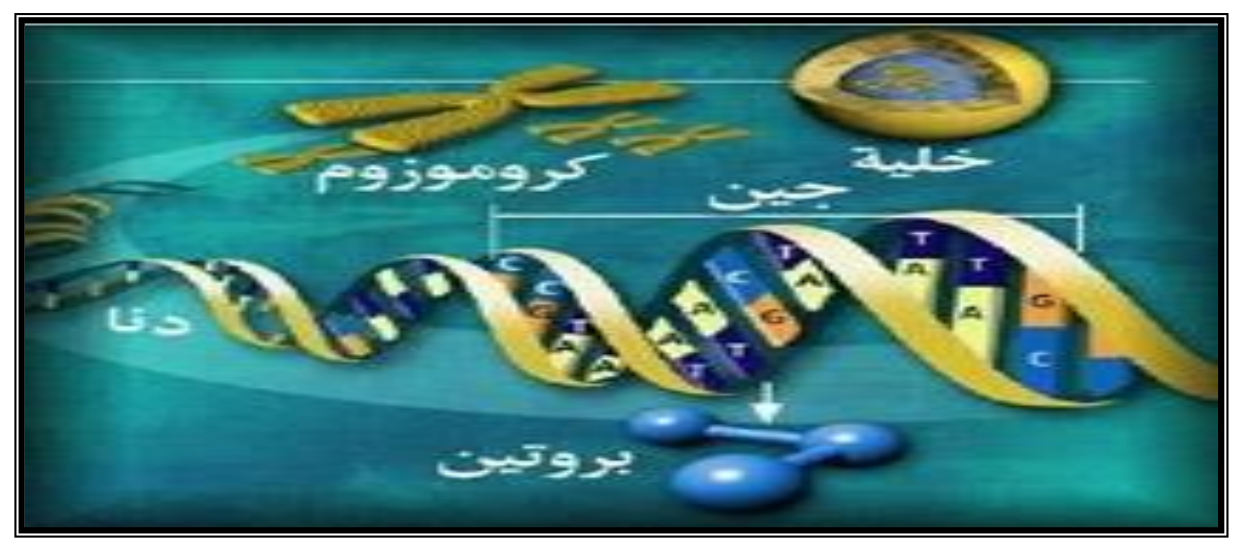

\section{الثكل(1) : شربط DNA}

لقد كثفت الدراسـات الحديثة أن للولب شريط DNA المزدوج، والذي يطلق عليـة أيضـا جديلة، لـه خصائص مذهلة، لا سيما في العلاقة بين التركيب والوظيفة التي تؤكد أن التصميم الدقيق لهذا اللولب المزدوج

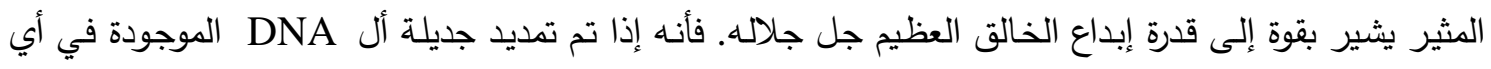

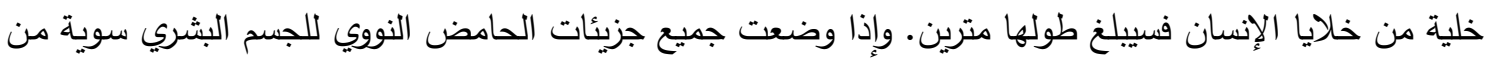

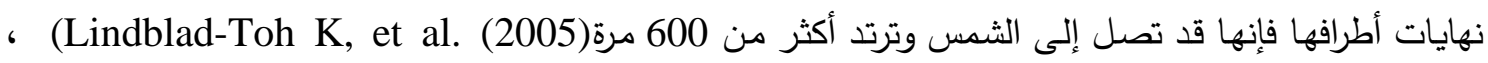
انظر الثكل(2) - نهات الثران 


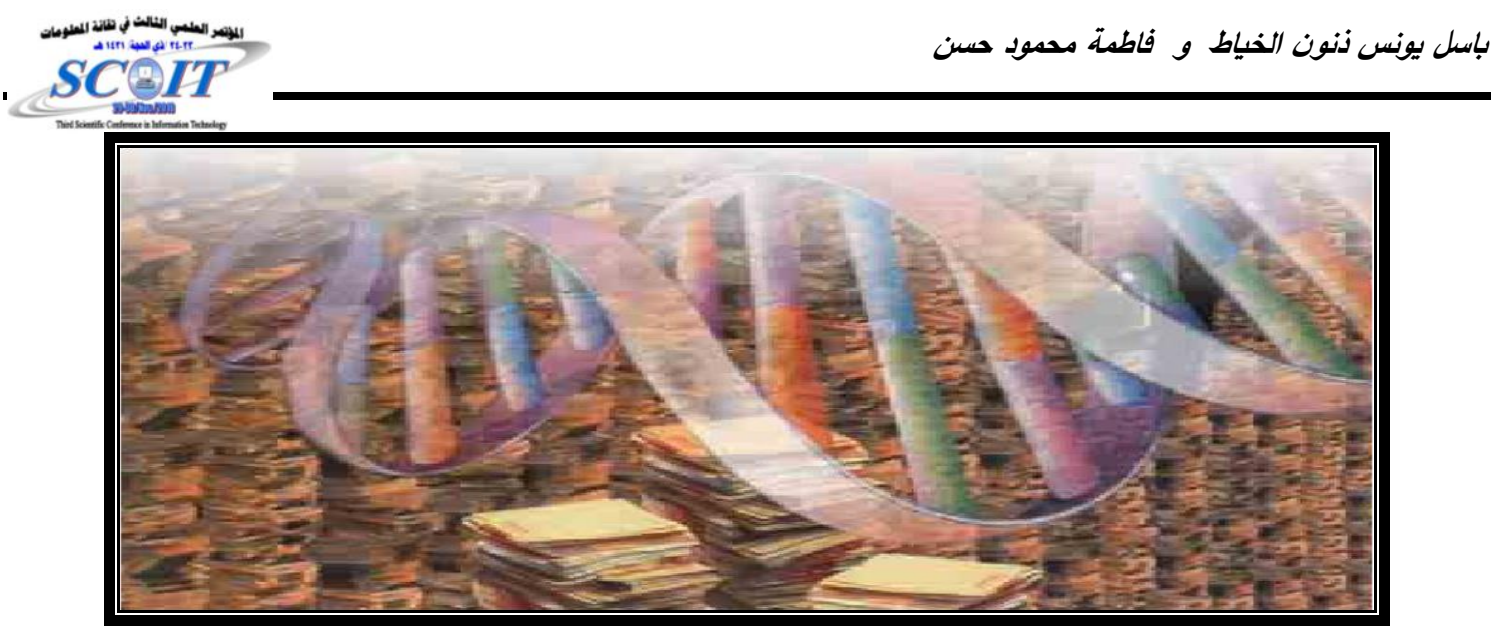

• DNA الثكل(2) : تمديد جديلة

إن الحامض النووي الرايبي منقوص ألأوكسجين يمثل المـادة الوراثيـة في نـواة الخليـة ، الحاويـة لكل

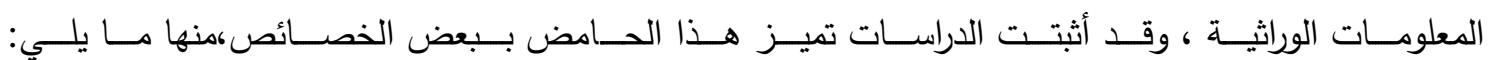

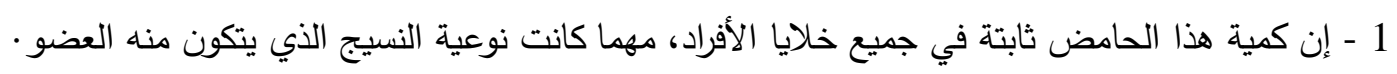

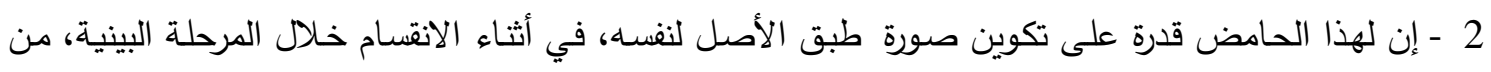

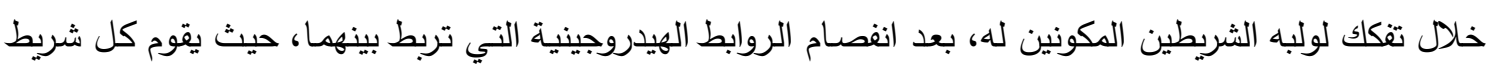
بعد ذلك بتكوين شريط مقابل، طبقاً للتجاذب النوعي للقواعد النيتروجينية، وينتج من هذا التكاثر الذاتي جزيئان متماثلان من هذا الحامض، مطابقان للجزيء الأصلي من حيث المكونات الأساسية.

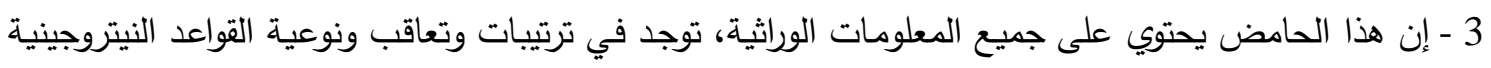

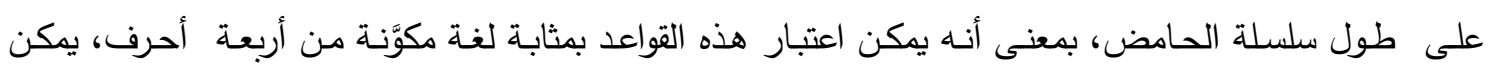

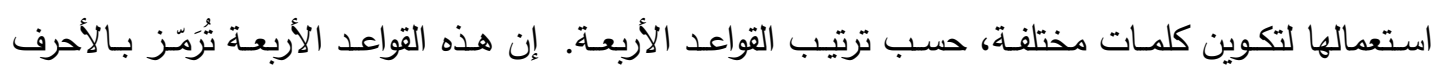
\{A,G,C,T\}

( (Meyer ( 2009))

3. المتتابعة الزمانية للحامض النووي DNA:

إن أل DNA هو مادة وراثية موجودة في سائر الكائنات الحية وتحمل الصفات المورثة تواترا جيلا بعد

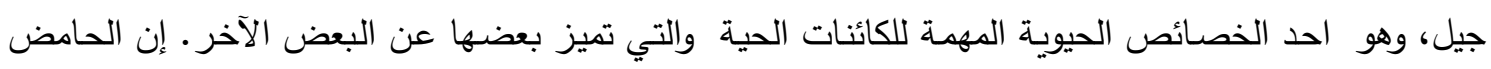

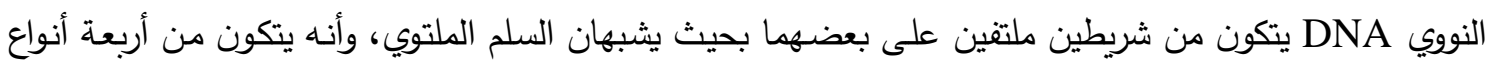

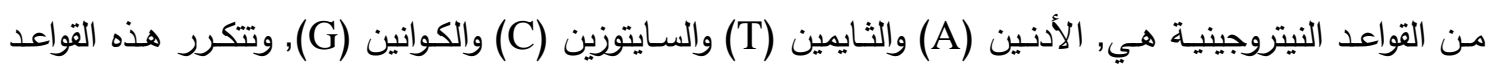

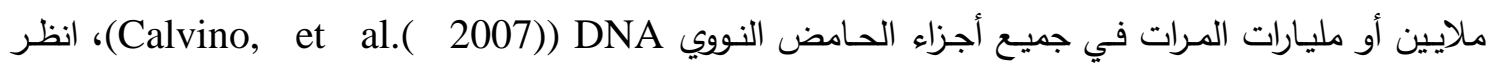

الشكل(3). 


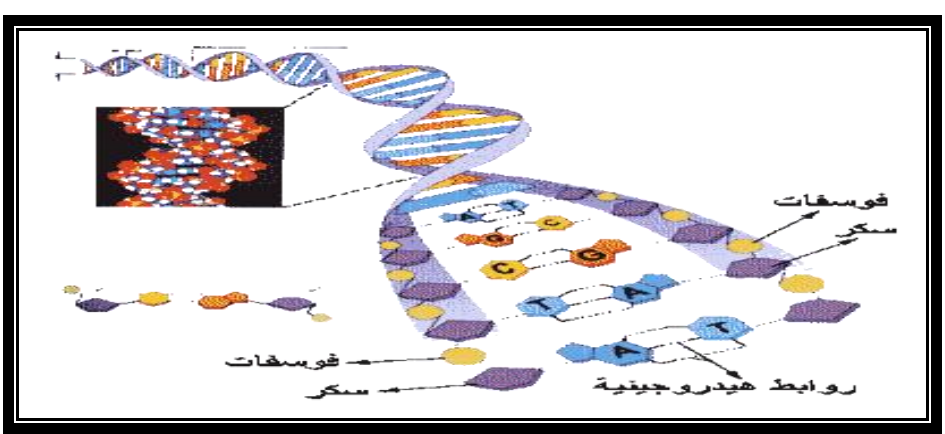

الشكل(3): تركيب الحامض النووي (DNA).

أن كل ثلاث قواعد نيتروجينية تعطي حامضا أمينيا واحدا ، كما أن عدد معين من الأحماض الامينية يؤدي إلى تكوين جين معين، وهذا الجين يكون مسئولا عن تكوين بروتين. وهذا البروتين بدوره له وظيفة محددة في معاني الحياة. يوجد أل DNA في نواة الخلية الحية كما يوجد عدد قليل منه في المايتوكوندريا (بيوت الطاقة)

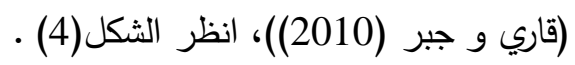

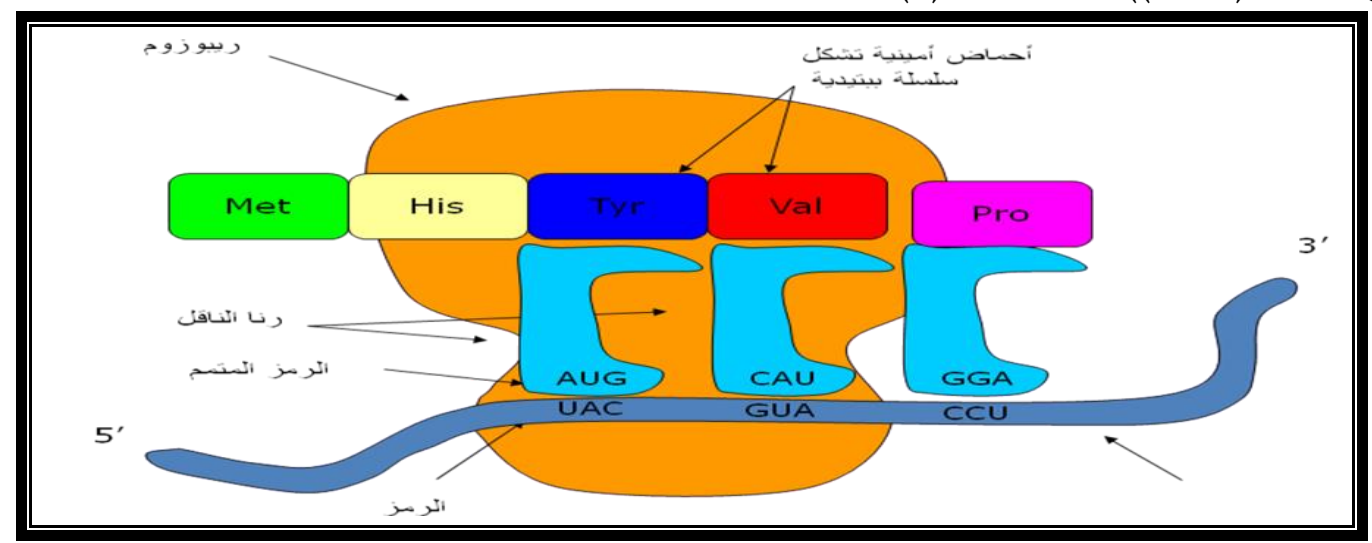

الثكل (4): يمثل مقطع للمادة الوراثية DNA والتي تتضمنها الأحماض الامينية.

4. تحليل مشاهدات الحامض النووي:

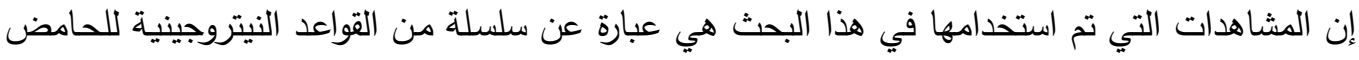

النووي DNA والموجودة في المايتوكندريا للإنسان الطبيعي • يبلغ حجم هذه المشاهدات 16571 قاعدة نيتروجينية

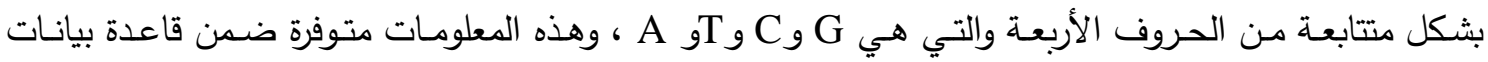
في مراكز عالمية مختصسة في الهندسة الوراثية ودراسة عمل الجينات والتي وفرت للباحثين عدداً (Data Base)

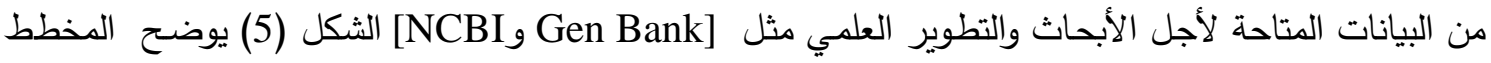
البياني لمراحل عملية تحويل المشاهدات الحيوية لأستخدامها في التطبيقات الحاسوبية. 


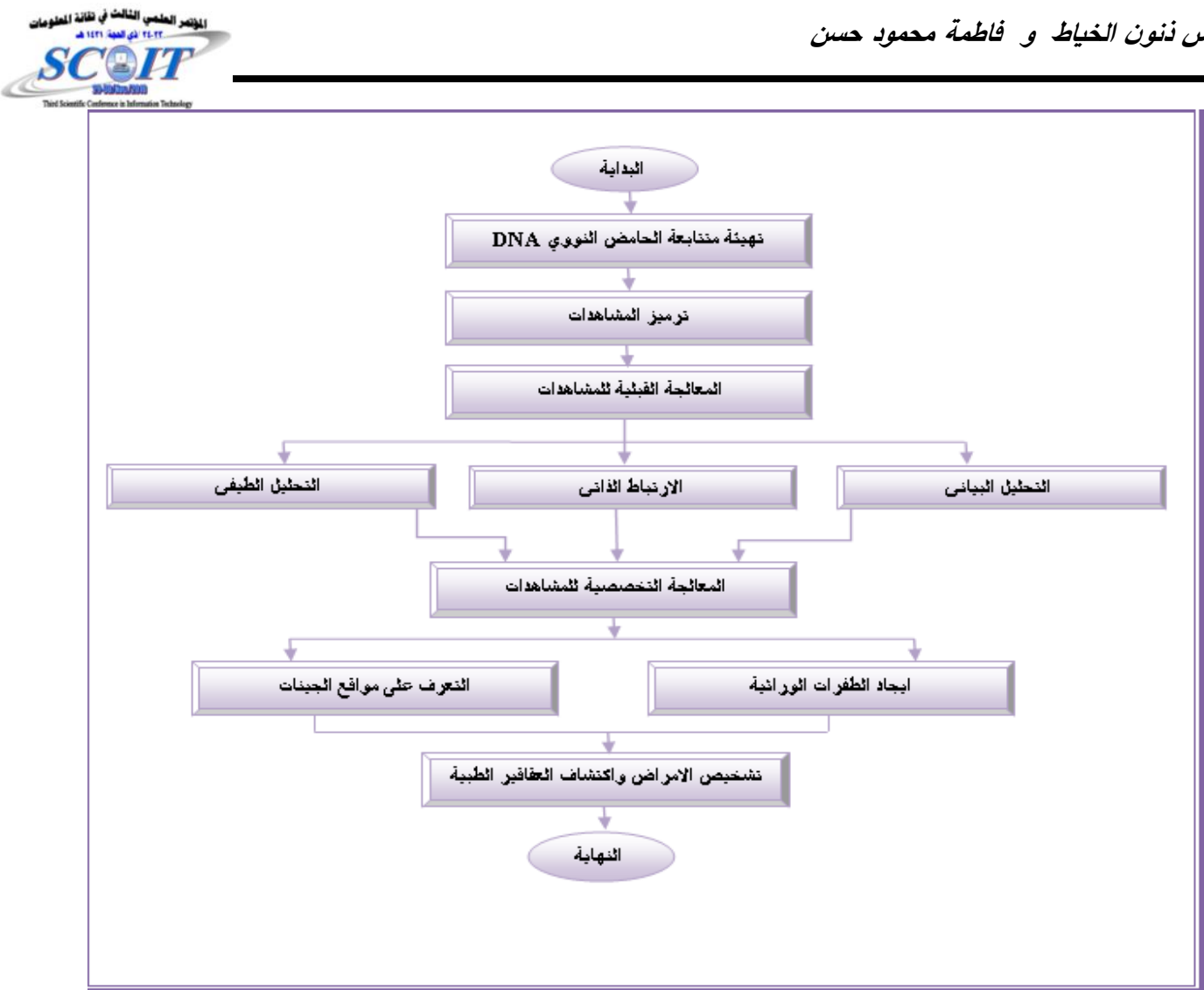

الشكل (5): المخطط البياني لمراحل عملية تحويل المشاهدات الحيوية لأستخدامها في التطبيقات الحاسوبية.

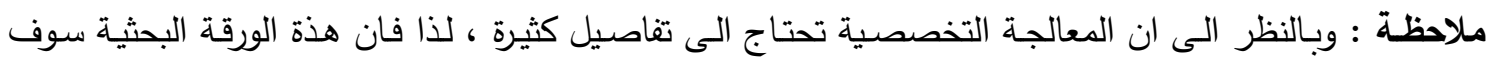
تخصص فقط على المعالجة القبلية .

\section{1 التحليل البياني :}

يمكن الاستعانة بالرسوم البيانية كأدوات مفيدة لأخذ فكرة أولية عن العلاقات الموجودة بين عناصر سلسلة القواعد النيتروجينية للحامض النووي. أن أول خطوة نحتاج إليها هي تحويل الرموز الحرفية الأربعة إلى أرقام ـ وقد تم إجراء هذا التحويل على النحو الأتي : 1 و $2 \equiv$

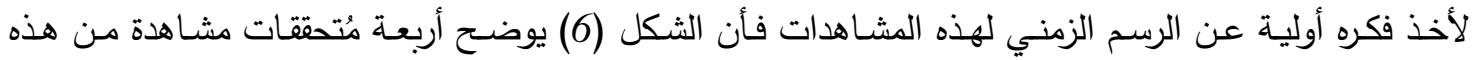
المتتابعة طول كل منها 200 ـ وكما هو واضح فأن نمط انتشار النقاط في كل من هذه المتتابعات الأربعة يختلف Non- عن الأخرى مما يثير إلى عدم وجود سلوك حتمي محدد لانتشار النقاط، وان هذه المشاهدات غير مُراوحة هئسة

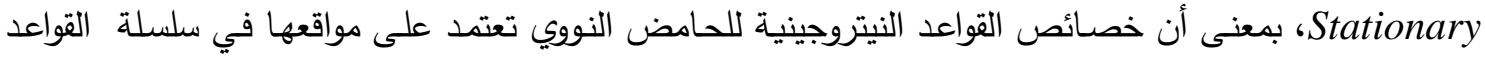
النيتروجينية للحامض النووي. ولو فرضنا الآن إن المتغير العشوائي (n) بيثل القاعدة النيتروجينية في الموقع n من سلسلة القواعد النيتروجينية للحامض النووي، وبفرض أن القاعدة النيتروجينية في الموقع n، (n) X النيتروجينية التي تسبقها ب k من المواقع، (1) X(n- X) فيمكننا أن نفترض النموذج الرياضي الآتي بينهما: $X(n)=g[X(n-k)] ; k=1,2,3, \ldots$

والثكل (6a) يوضـح شكل الانتشار بين (n) الدراسة. أما الثكل (6b) فيوضـح شكل الانتشـار بين (n) 
للمشاهدات نفسها. وكما هو واضح من الأشكال فهناك انتقالات بين جميع القواعد النيتروجينية الأربعة .من ناحية أخرى فمن الواضح أن العلاقة بين هذه القواعد تبدو ذات تركيب ذو طبيعة معقدة يختلف باختلاف قيمة k.

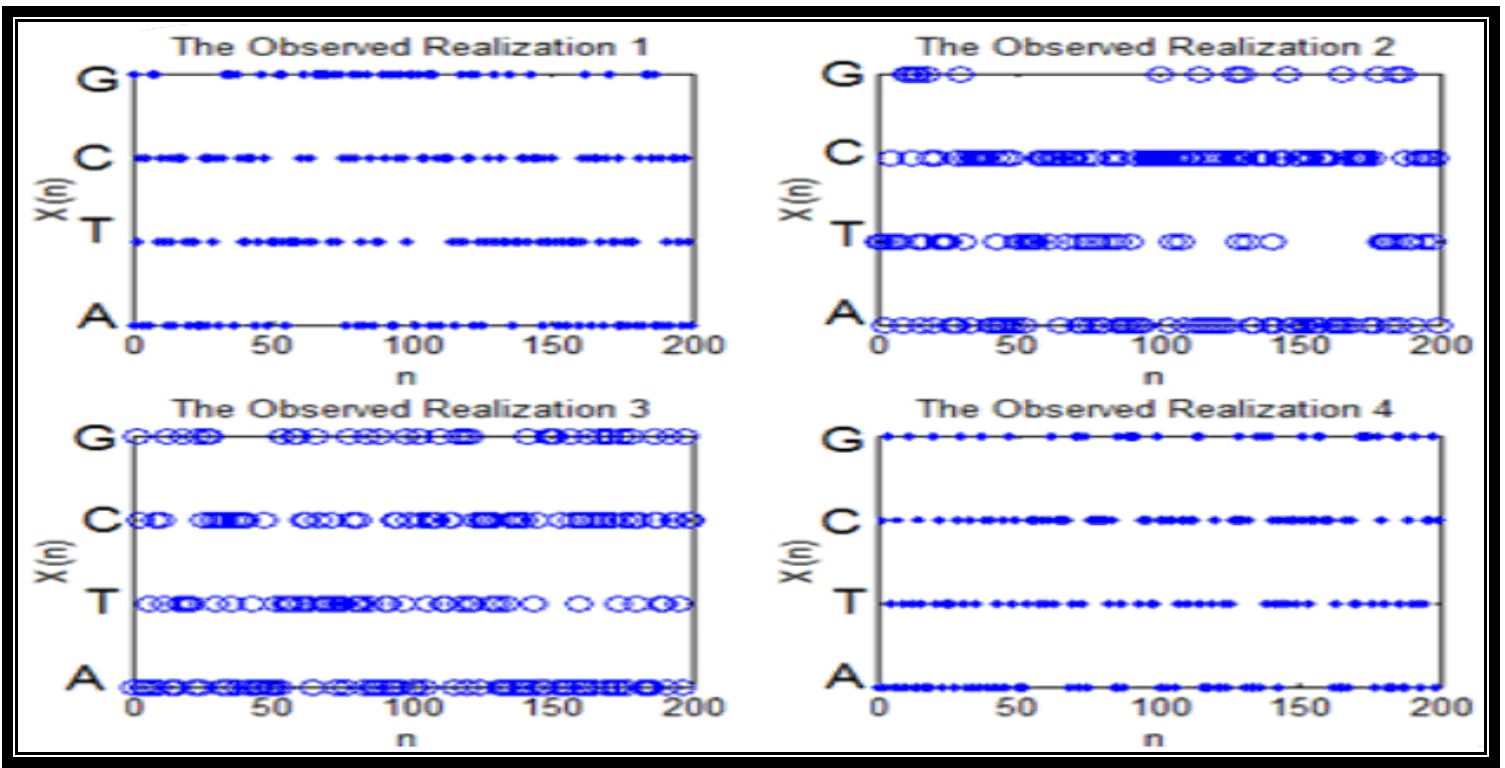

الثكل (6): أربعة مُتحققات مشاهدة من هذه المتتابعة طول كل منها 200 ـ.
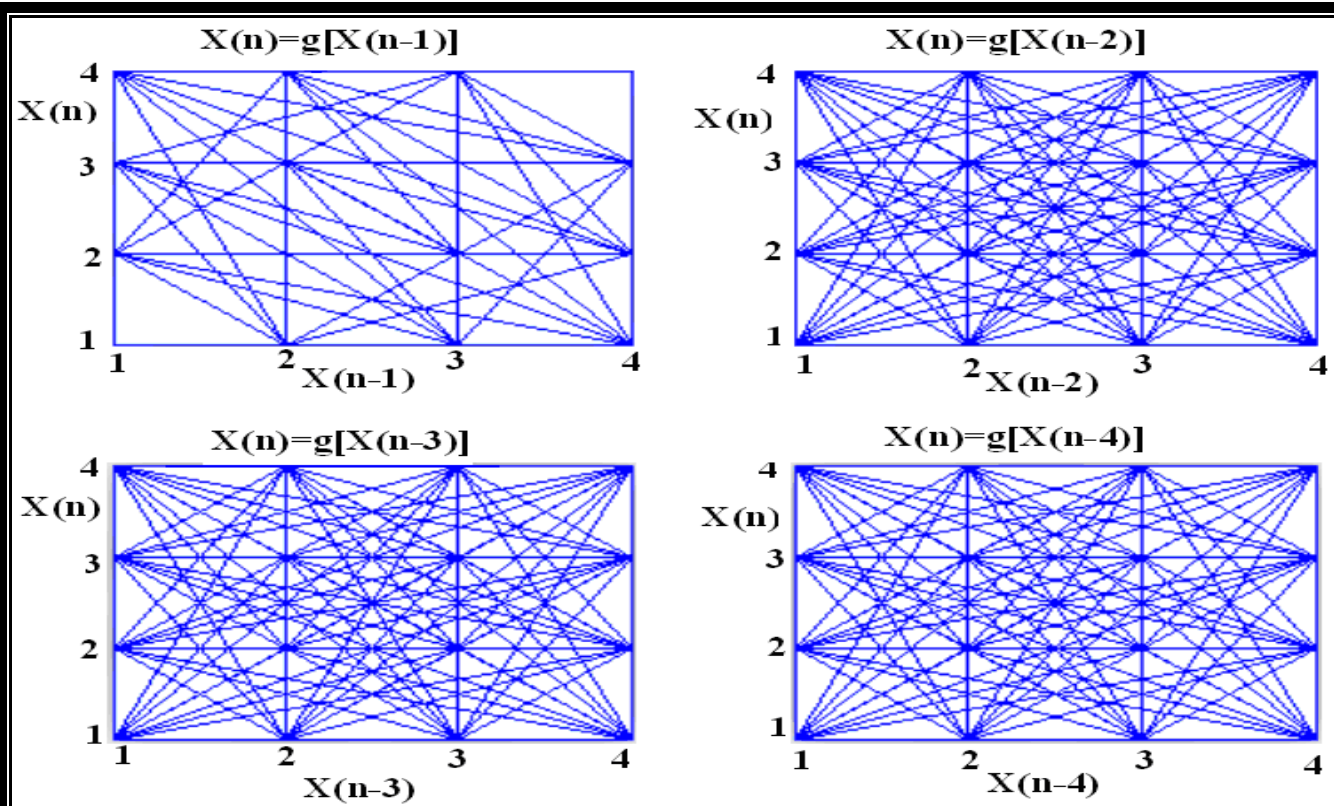

الثكل (6a): شكل الاتتشار بين (n) النيتروجينية للحامض النووي. 


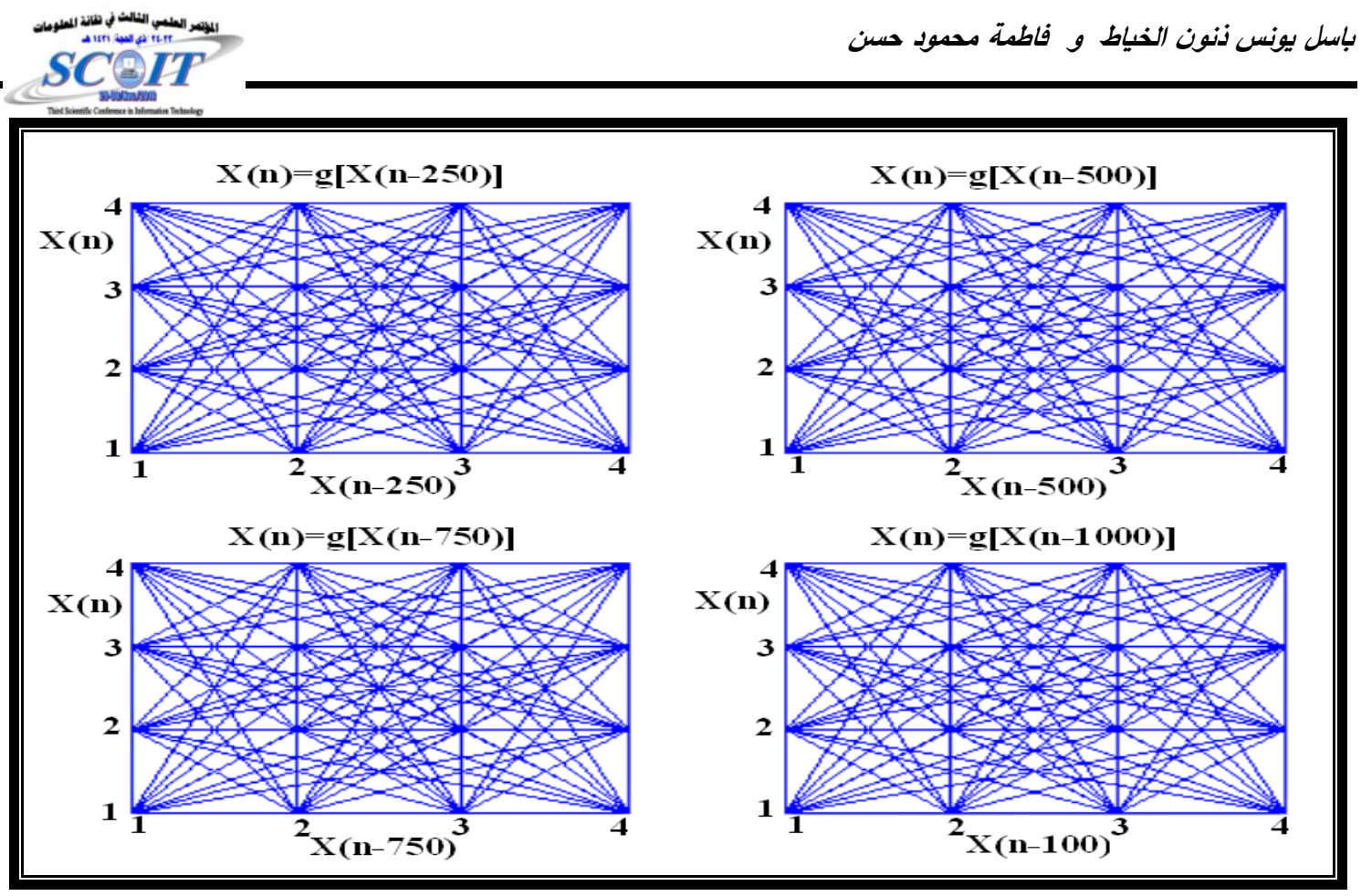

الثكل (6b): شكل الاتتشار بين (n) القواعد النيتروجينية للحامض النوائ.

ويمكن تطوير الفكرة السـابقة لمحاولـة دراسـة العلاقة بين القاعدة النيتروجينية في الموقع n وقاعدتين نيتروجينيتين في موقعين آخرين وذلك بفرض أن هذه العلاقة على النحو الآتي: $X(n)=G[X(n-k x), X(n-k y)] ; k x, k y=1,2,3, \ldots$

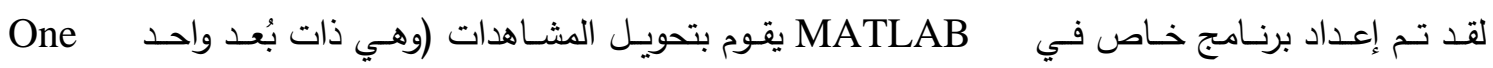

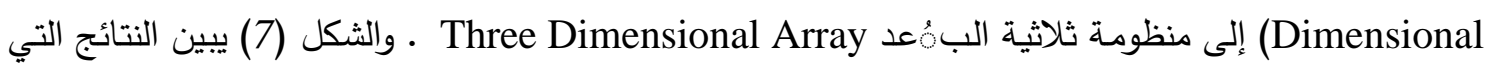
حصلنا عليها لقيم مختارة من Bx و Surface واضحة من خلال هذه الإشكال . 


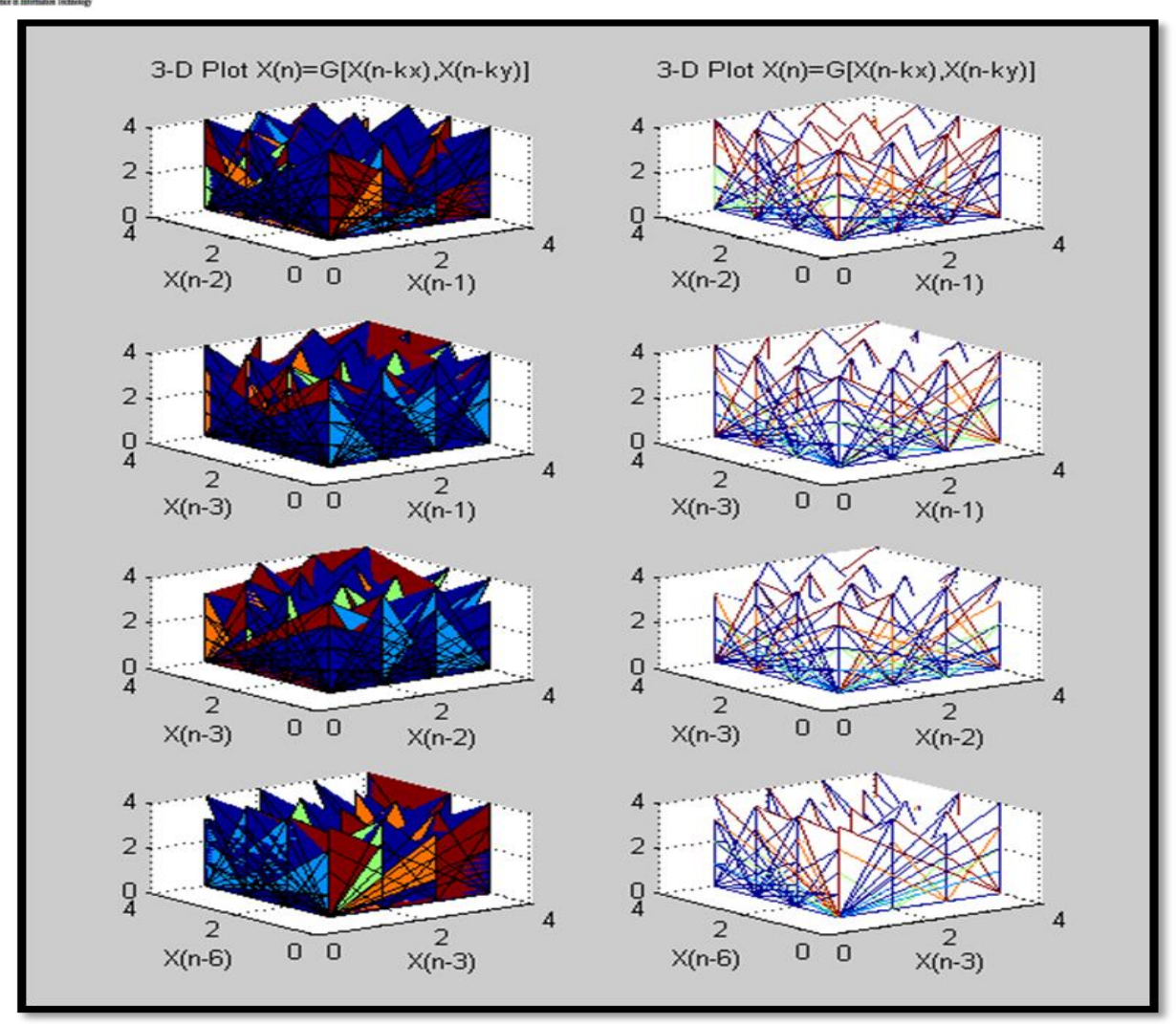

الثكل (7): الثبكة والسطح الخاص والمقابل للقيم المختارة من kx و ky .

: Autocorrelation Function (ACF) الارتباط الذاتي 4.2

تستخدم داله الارتباط الذاتي في تحليل مشاهدات المتسلسلات الزمنية. إذا كانت $\left\{x_{1}, x_{2}, \ldots . ., x_{T}\right.$ مشاهدات من متسلسلة زمنية معينة، فأن داله الارتباط الذاتي يمكن تقديرها على النحو الأتي (الخياط (2010)):

$$
\hat{\rho}(k)=\frac{\sum_{t=1}^{T-k}\left(x_{t}-\bar{x}\right)\left(x_{t-k}-\bar{x}\right)}{\sum_{t=1}^{T}\left(x_{t}-\bar{x}\right)^{2}} ; k=1,2,3, \ldots,(T-1)
$$

إذ إن

إن داله الارتباط الذاتي هي مقياس مجرد من الوحدات وتتراوح قيمها بين 1土 , فإذا اقتربت قيمته من 1+ فأن

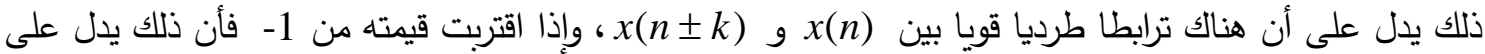

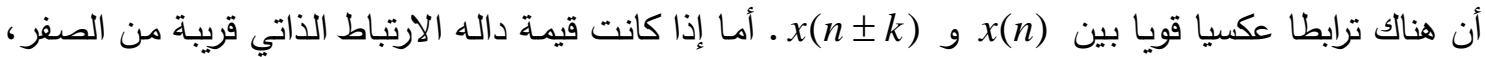
فان هذا دليل على عشوائية المتسلسلة. إن حدي الثقة Confidence Limits لدالة الارتباط الذاتي عند مستوى المعنوية 5\% وتحت فرض عشوائية المتسلسلة الزمنية هي 
أن دراسة الارتباط Correlation يعد احد الجوانب المهمة لدراسة العلاقة بين عناصر أي متتابعة، ويمكن انجاز ذلك من خلال ما يطلق عليه عادة اختبار العشوائية Test of Randomness. إن اختبار العشوائية يمكن انجازه بوساطة دالة الارتباط الذاتي المقدرة. وتجدر الإثارة، إلى أن العناصر الأكثر أهمية من دالة الارتباط الذاتي تكون

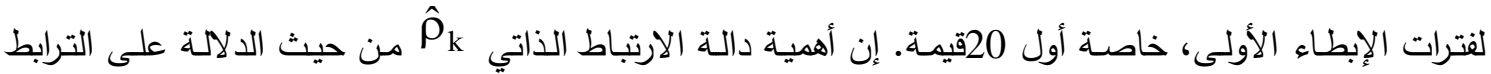
الداخلي لقيم المشاهدات تتناسب مع اقتراب قيمة k من نقطة الأصل k=0. فكلما اقتربت قيمة k من الصفر كلما

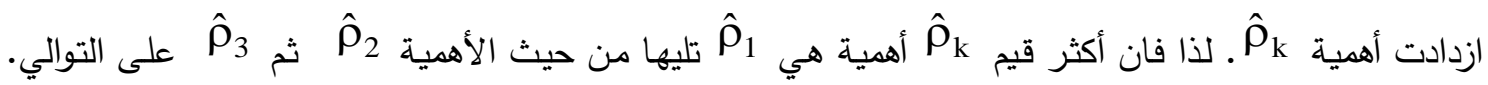

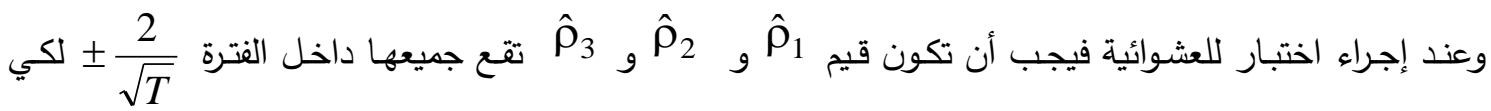
تكون فرضيتنا لعشوائية المشاهدات مقبولة بمستوى معنوية 5\%. أما إذا وقعت في الأقل أي من 1 م أو خ مارج الفترة م $_{3}$

داخل فترة الثقة.

لقد تم تقدير و رسم دالة الارتباط الذاتي لمشاهدات القواعد النيتروجينية للحامض النووي وذلك بالاستعانة

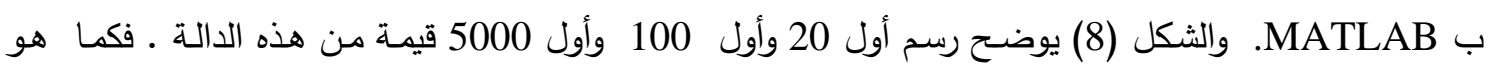
واضح فأن الترابط الداخلي موجود في فترات الإبطاء القربية والمتوسطة والبعيدة. من ناحية أخرى فأن هذا الترابط

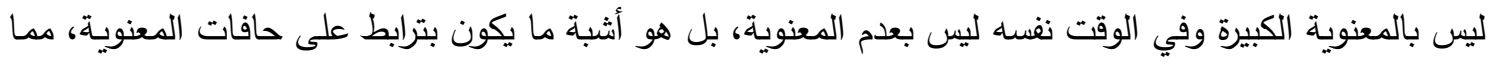

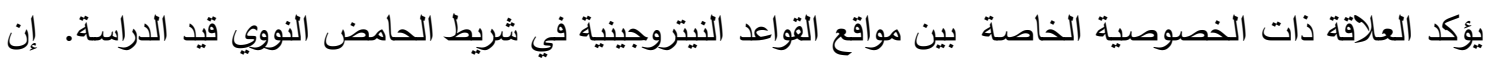

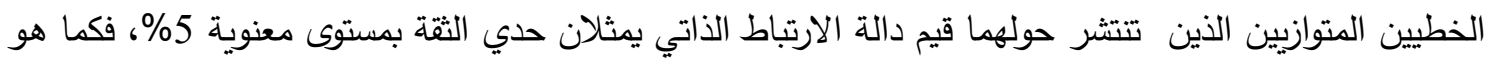

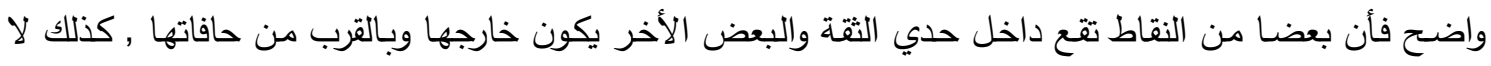
توجد قيم لدالة الارتباط الذاتي تزيد عن 0.1 0.1 . كل هذا يشير إلى أن هذه المشاهدات لا يمكن اعتبارها عشوائية وغير مترابطة مسع بعضها البعض, من ناحية أخرى فلا يوجد ترابط قوي يمكن الاستتاد علية لدراسة العلاقة بين

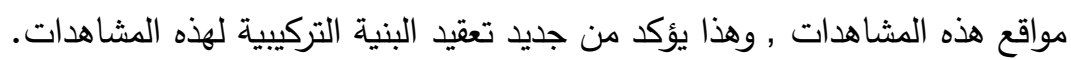

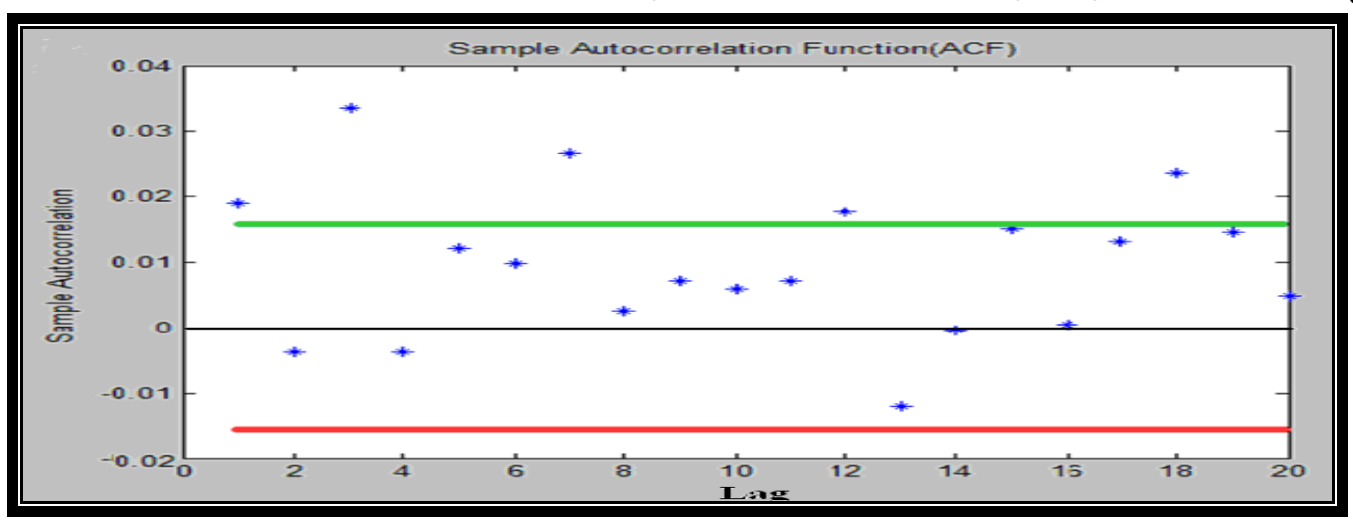

الثكل (8a): دالة الارتباط الذاتي لمشاهدات القواعد النيتروجينية للحامض النووي لأول 20 قيمة. 


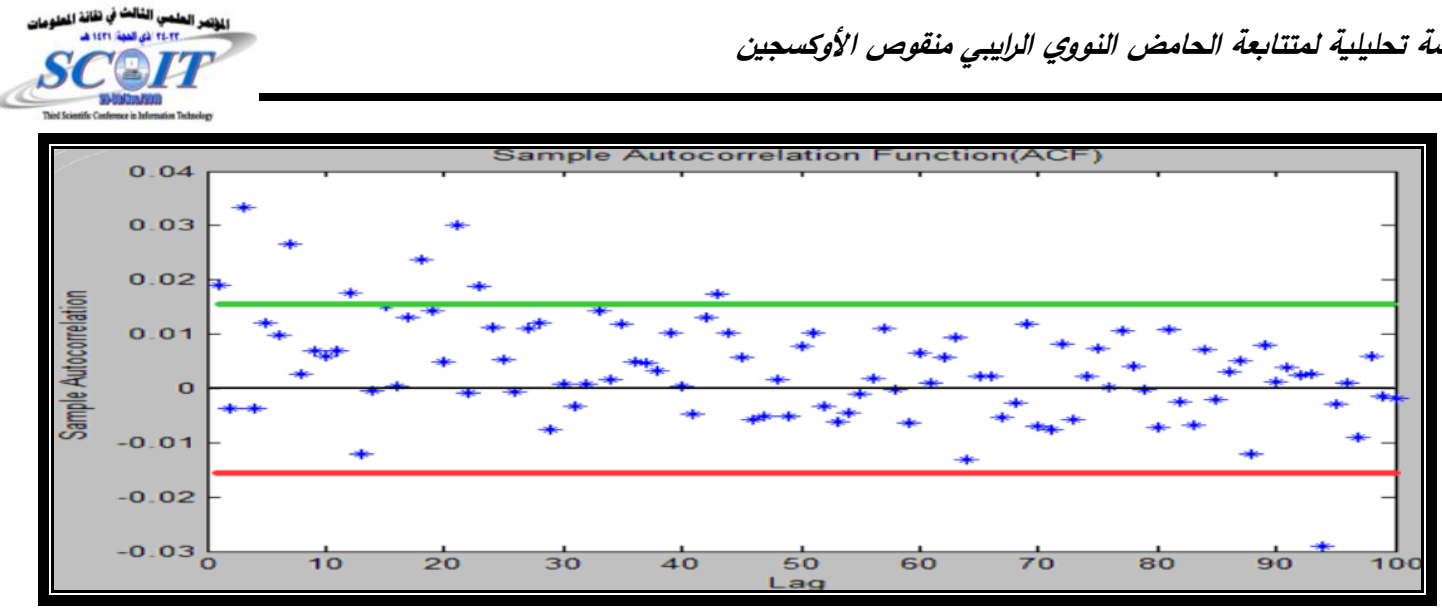

الثكل (8b): دالة الارتباط الذاتي لمشاهدات القواعد النيتروجينية للحامض النووي لأول 100 قيمة.

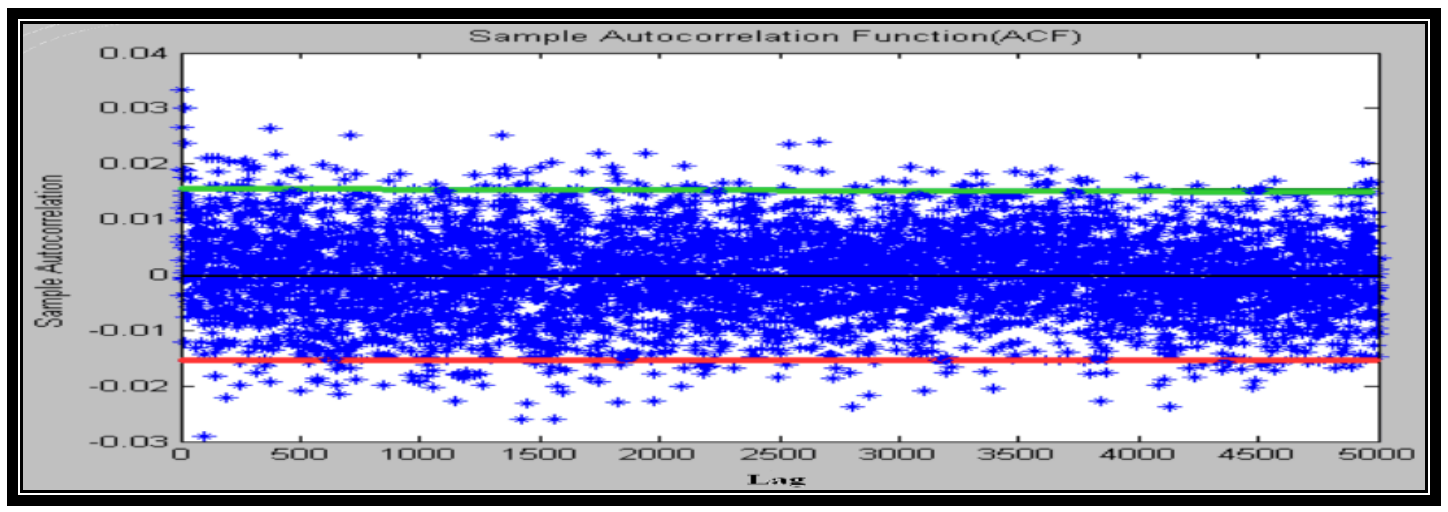

الثكل (8c): دالة الارتباط الذاتي لمشاهدات القواعد النيتروجينية للحامض النووي لأول 5000 قيمة.

4.3 التحليل الطيفي Spectral Analysis:

Normalized Power Spectral Density الشكل (10) يوضح مقدر لدالة كثافة الطيف المعيارية [ لمتتابعة الحامض النووي الرايبي منقوص الأوكسجين. وقد تم استخدام المقدر الآتي لهذا الغرض لوضية Function :(Chatfield [1980)

$$
f(w)=\frac{1+2 \sum \hat{\rho}_{k} \cos \left(k w_{p}\right)}{2 \pi} ;-2 \pi \leq w \leq 2 \pi, w_{p}=\frac{2 \pi p}{T} ; p=1,2, \ldots, \frac{T}{2} .
$$

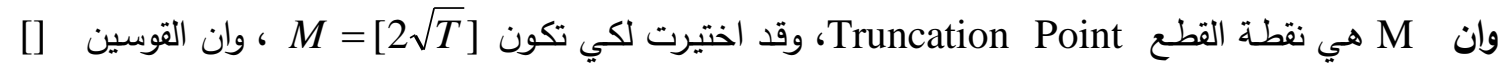
يعنيان إن يؤخذ الجزء الصحيح من المقدار المحصور بينهما. 


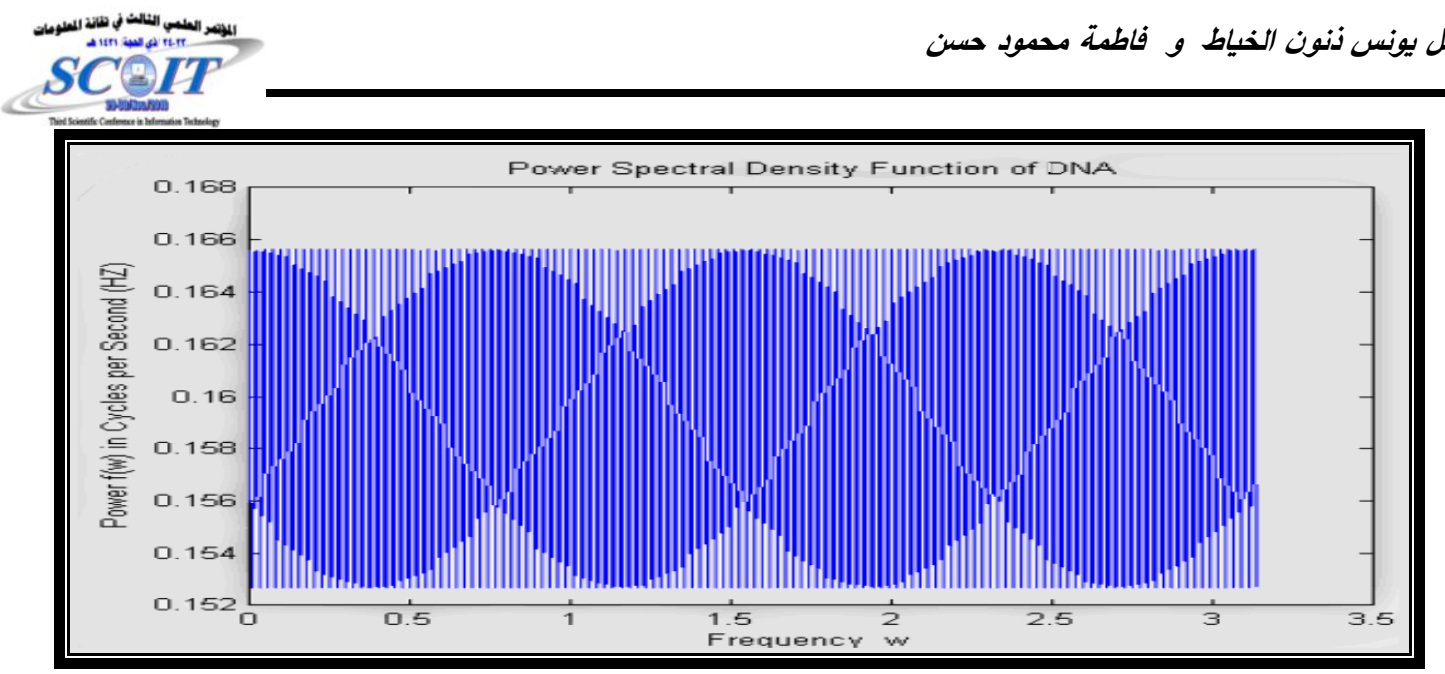

الثكل (9) : مقدر دالة كثافة الطيف المعيارية لمتتابعة الحامض النووي الرايبي منقوص الأوكسجين.

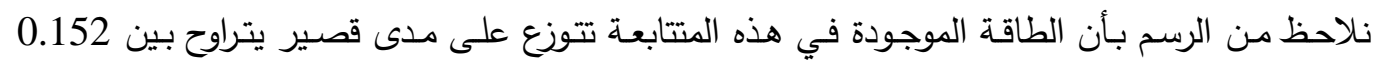

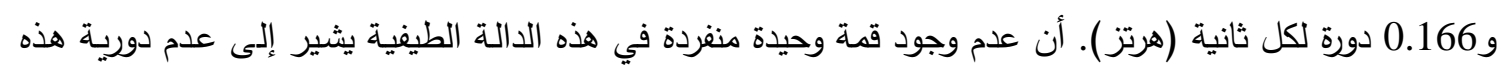

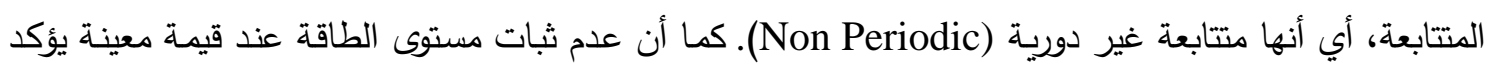

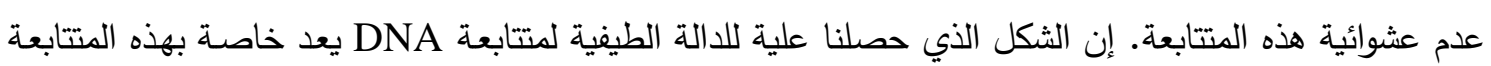
ويشير إلى أن هذه المتتابعة تتمتع ببنية تركيبة بالغة التعقيد خاصة بهان النها.

4.4 تقدير المَرتبة Estimation of Order:

يعد تقدير مَرتبة سلسلة ماركوف من المسائل بالغة الأهمية في التطبيقات الواقعية، لـا لها من علاقة بذاكرة السلسلة التي تتحكم ببعد النموذج. يقال للعملية التصادفية \}...

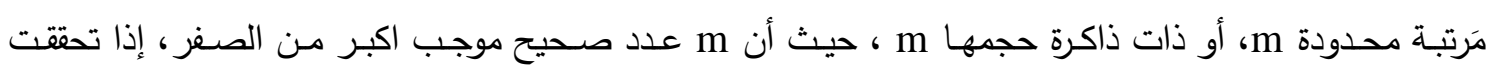

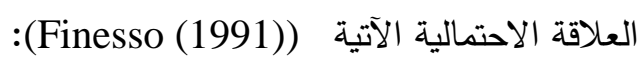

$$
\begin{aligned}
& P=\left(X_{t+1}=j \mid X_{t}=i_{o}, X_{t-1}=i_{1}\right. \\
& =P\left(X_{t+1}=j \mid X_{t}=i_{o}, X_{t-1}=i_{1}, \ldots, X_{t-m}=i_{m}\right) \text {, }
\end{aligned}
$$

حيث أن ويمكن تعريف المَرتبة بأنها اقل عدد صحيح موجب ممكن لعدد الحالات السابقة المباشرة التي تعتمد

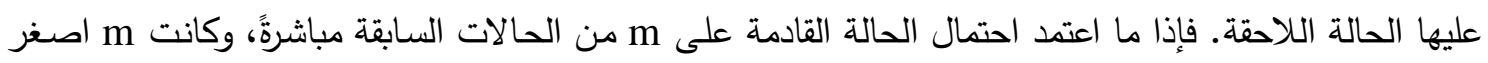
عد صحيح موجب مدكن، عندئذ فان m ستمثل مرتبة سلسلة ماركوف، وبحيث تحقق العلاقة (5). وقد تكون

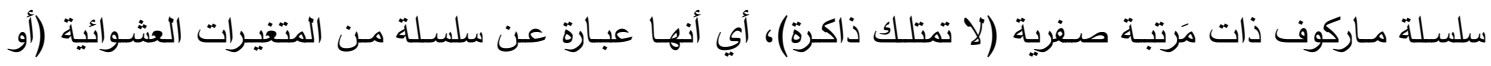

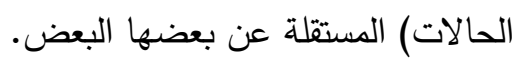

لقد ظهرت في أواخر ستينيات وسبعينيات القرن العشرين معايير للمعلومـات تعـالج مسالة تقدير مَرتبـة سلسلة

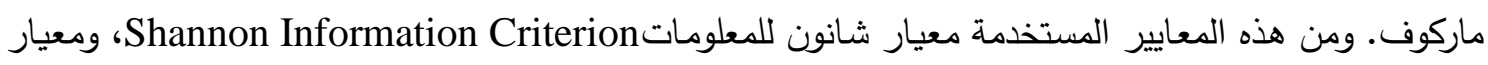

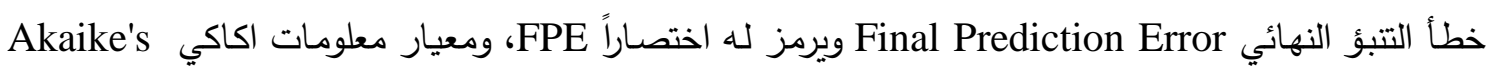

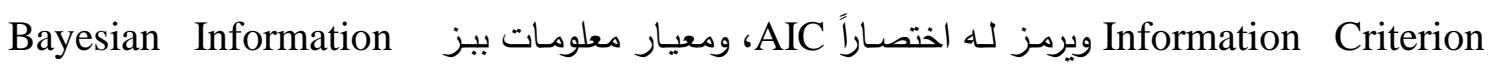
Criterion 
النووي منقوص الأوكسجين DNA. إن هذا المعيار هو مقياس لانحرافات النموذج عن النموذج الحقيقي. وان

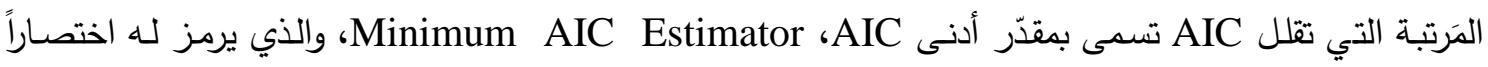

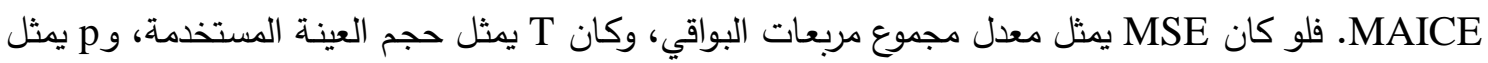

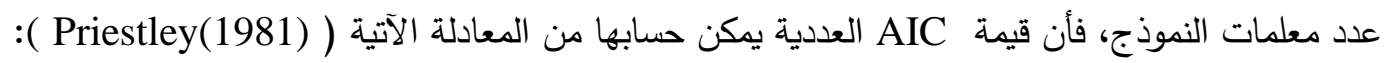
$\mathrm{AIC}(\mathrm{p})=\mathrm{T} \ln (\mathrm{MSE})+2 \mathrm{p}$

إن الصيغة المكافئة لمعيار AIC في مجال تقدير مراتب سلاسل ماركوف تكون على النحو الأتي ( الكسو (2005)):

$$
\left.\begin{array}{rl}
R(k) & ={ }_{k} \eta_{L}-2(\text { degrees of freedom) } \\
{ }_{k} \eta_{L} & ={ }_{k} \eta_{k+1}+\ldots+{ }_{L-1} \eta_{L} \\
& =\nabla^{2} k_{k+2}+\ldots+\nabla^{2} m_{L+1} \\
& =\nabla k_{L+1}+\ldots+\nabla k_{k+1} \quad(-1 \leq \mathrm{k}<\mathrm{L}) \\
& =-2 \log \lambda_{\mathrm{k}, \mathrm{k}+1}-2 \log \lambda_{k+1, k+2}-2 \ldots-2 \log \lambda_{L-1, L}
\end{array}\right\}
$$

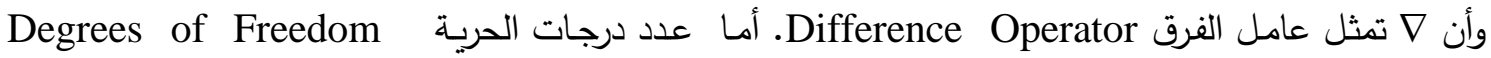
Degrees of freedom $=\nabla N^{L+1}-\nabla N^{k+1}$ فيكن حسابها من الصيغة الآتية (1975, Tong):

$$
\equiv N^{L+1}-N^{L}-N^{k+1}+N^{k}
$$

حيث أن N تمثل عدد الحالات الممكنة للسلسلة في فضاء العينة . من المعروف جيدا أن معيار AIC يجهز بمقدر غير متسق Not Consistent Estimate للمَرتبة الحقيقية

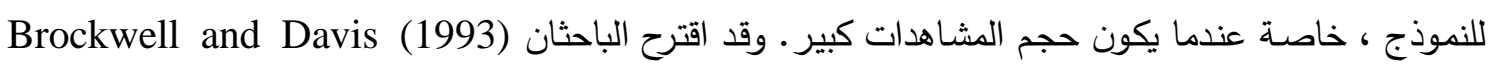
تصحيحا لمعيار AIC وأوصيا باستخدامه عندما يكون حجم المشاهدات كبير • إن معيار AIC المصحح يرمز له له

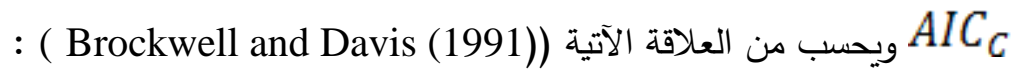

$$
A I C_{C}=A I C+\frac{2(k+1)(k+2)}{(n-k-2)}
$$

لقد تم تطبيق معياري AIC و AIC المعدلة على مشاهدات الحامض النووي الرايبي منقوص الأوكسجين

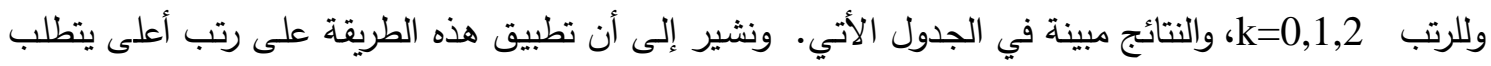

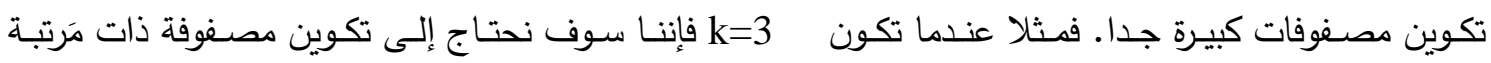
256*256 ـ أما عندما تكون k=4 فأنة سوف يتطلب تكوين مصفوفة ذات مَرتبة 1024 1024.

• الجدول(1): تقدير مَرتبة متتابعة ألحامض النووي منقوص الأوكسين|
\begin{tabular}{|l|l|l|l|}
\hline k & $\begin{array}{l}\text { Degrees of } \\
\text { freedom }\end{array}$ & $\mathbf{R}(\mathbf{k})$ & $A I C_{C}$ \\
\hline 0 & 45 & 351.2360 & 351.2362 \\
\hline 1 & 180 & 147.1142 & 147.1149 \\
\hline 2 & 144 & 53.2684 & 53.2699 \\
\hline
\end{tabular}


نلاحظ أن هناك هبوط قوي في قيم AIC و AIC مما يؤكد الاعتمادية بين مواقع مَرتبة متتابعة

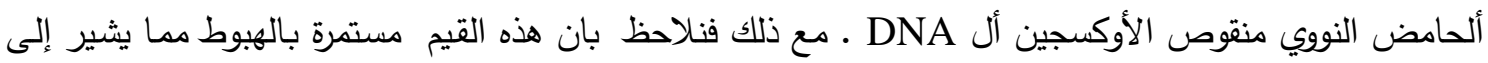
أن المَرتبة الحقيقية لهذه المتتابعة هي أكثر من2، إلا أن الصعوبات في تكوين المصفوفات لم لم تمكننا من الوصول إلى التَرتبة الحقيقية. ولعل استخدام التقنيات الذكائية يكون احد الوسائل التي توصل إلى المَتبة الحقيقية، ولكن هذا خارج مجال بحثنا.

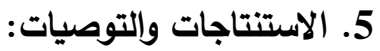

تضــنت هـذه الورقـة البحثيـة مقدمـة عامـة عـن المعلوماتيـة الحيويـة، وأهـافها ومضــامينها ومجالاتهـا

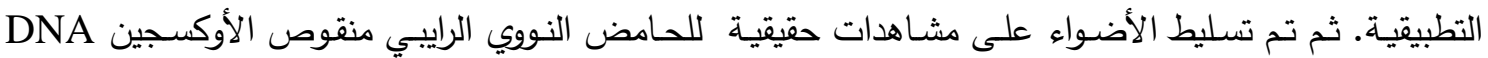

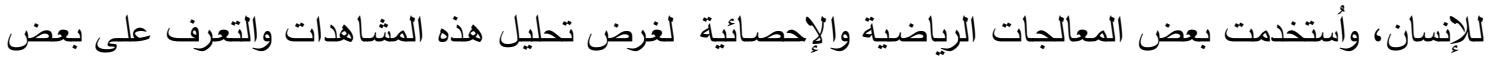
سماتها وخصائصها. والاستتتاج الواضح بعد كل التحليلات التي أجريت في هذه الورقة البحثية هو أن هذه المتتابعة

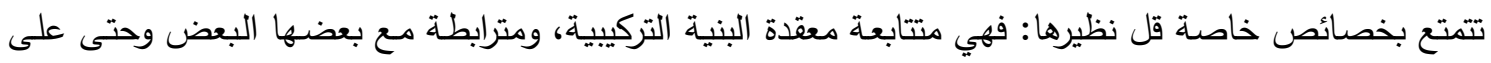
الفترات البعيدة المدى. إن الأهمية الكبيرة للمتتابعات الزمانية لسلاسل الحامض النووي الرايبي منقوص الأوكسجين

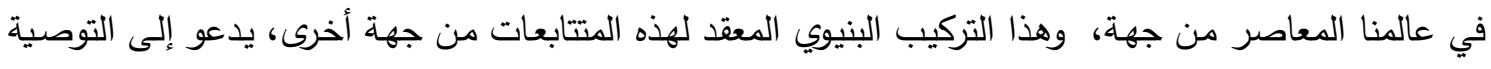
بتوجّه بحثي اكبر، وبالتعاون مـ التخصصات ذوات العلاقة، باتجاه لمتتابعات الزمانية لسلاسل الحامض النوري

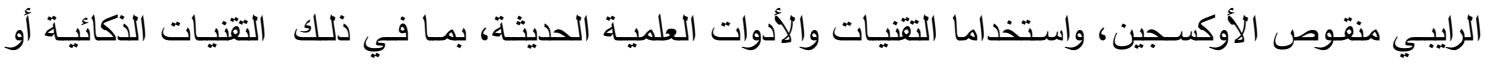

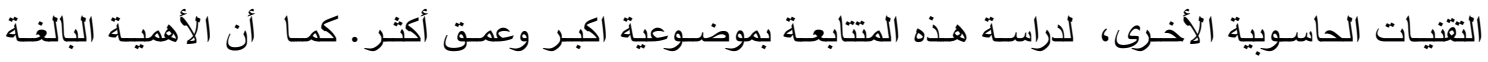
للمعلوماتية الحيوية، وكما سلطنا الضوء على بعض جوانبها في هذه الورقة البحثية، تدعونا للتوصية بإنشاء مركز

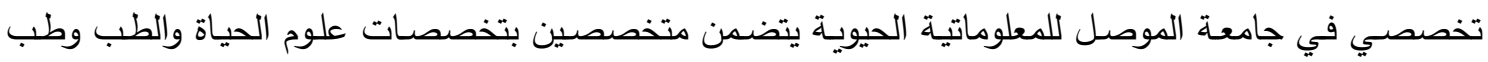
الأسنان والطب البيطري والزراعة، إضافة إلى تخصصات الحاسوب والرياضيات والإحصاء.

\section{المصادر}

الخياط ، باسل يونس ذنون (2010). "النمذجة الماركوفية ميع تطبيقات عملية"، دار الكتب للطباعة 
الكسو ،ابتهاج عبد الحميد (2005)."استخدام الثبكات العصبية في تقدير رتب سلاسل مـاركوف مـع

التطبيق على سلسـلة جبل بطمـة في محافظـة الموصل "،أطروحة دكتوراه غير منشورة ،كليـة علوم

الحاسبات والرياضيات ، جامعة الموصل.

قاري، سمير بن حسن محمد و جبر ، جميل فوزي جميل (2010). " مدخل والى الوراثة البشرية" دار

الفكر للطباعة والنشر , مكة المكرمة .

قاسم، عمر صابر (2009)." تطبيق التقنيات الذكائية في المعلوماتية الحيويـة "، أطروحة دكتوراه غير

منشورة، كلية علوم الحاسبات والرياضيات، جامعة الموصل.

[5]. Brockwell,R.J. and Davis, R.A. (1991). "Time Series: Theory and Methods",Springer, New York.

[6]. Calvino, M., Gomez, N. and Mingo, L.F.,(2007), "DNA Simulation of Genetic Algorithms: Fitness Computation”, International Journal ,Information Theories \& Applications, Vol.14.

[7]. Chatfield, C (1980):"The Analysis of Time Series: An Introduction", Chapman and Hall Ltd, London.

[8]. Finesso, Lorenzo. ,(1991): “Consistent estimation of the order for markov and hidden markov chains", Ph. D. , Dissertation.

[9]. http://www.ncbi.nlm.nih.gov/Education/BLASTinfo/information3.html

[10]. Lindblad-Toh K, et al. (2005). "Genome sequence, comparative analysis and haplotype structure of the domestic dog .".Nature . 19-803:(7069) 438.

[11]. Meyer ,S. C.(2009). "Signature in the Cell: DNA and the Evidence for Intelligent Design", HarperColline_books, ISBN 978-0-06-189421-3, USP

[12]. Priestley, M. B. ,(1981): "Spectral analysis and time series", Academic Press, INC. ,(London) LTD.

[13]. Shoemaker, J.S. and Lin, S.M., (2005), "Methods of Microarray Data Analysis IV”, Springer Science + Business Media, Inc.

[14]. Tong, H. ,(1975): "Determination of the order of a Markov chain by using Akaike's information criterion", J. Appl. Prob. 12, 488-497. 